\title{
Free deep inferior epigastric perforator flap after abdominal liposuction: reconsidering a contraindication
}

\author{
Peter James Mankowski, Jonathan Kanevsky, Anne-Sophie Lessard, Teanoosh Zadeh \\ Division of Plastic and Reconstructive Surgery, McGill University Health Centre, Montreal, Quebec H3G 1B3, Canada.
}

Address for correspondence: Mr. Peter James Mankowski, Division of Plastic and Reconstructive Surgery, McGill University Health Centre, Montreal, Quebec H3G 1B3, Canada. E-mail: peter.mankowski@mail.mcgill.ca

\begin{abstract}
Autologous breast reconstruction with perforators has been previously avoided in tissues that have undergone liposuction. We present a case series and literature review of breast reconstruction with deep inferior epigastric perforator (DIEP) flaps after abdominal wall liposuction. An MEDLINE search was performed for all relevant articles describing breast reconstruction with DIEP flap technique following the abdominal wall liposuction. Key search words used included "DIEP", "DIEAP", "deep inferior epigastric perforator", "liposuction" and "free flap". All published data on the topic from 1965 to December 2014 were reviewed. Articles were assessed for reports of clinical cases, complications, age, liposuction amount, time since liposuction and number of perforators for comparison. We have also presented 2 patients who underwent a DIEP procedure with a previous history of liposuction. Eight cases of autologous breast reconstruction using a DIEP flap after liposuction were identified in the literature in addition to the presented cases. The preoperative and postoperative course was uneventful in all cases except one patient who had a mild cellulitis managed with antibiotics and a second patient with a drainable hematoma. The average age was 52 years \pm 6.4 years old, one perforator was used in all cases except one where 2 were used, and the average amount of total liposuction was 1,084 mL. No major complications were reported. Previous liposuction is not an absolute contraindication for free-flap breast reconstruction. Preoperative management should include evaluation of suitable perforators by duplex ultrasound or computed tomography angiography. Larger case series are needed to better understand the safety of perforator flaps after liposuction.
\end{abstract}

Key words:

Breast reconstruction, deep inferior epigastric perforator, flap, liposuction

\section{INTRODUCTION}

Over the past decade, there has been an increase in breast reconstruction among women who have previously had liposuction. ${ }^{[1]}$ Raising a perforator flap is generally contraindicated after abdominal liposuction due to possible damage of the perforators that supply the flap's vascularity. ${ }^{[2]}$ Numerous articles have already

\begin{tabular}{|l|l|}
\multicolumn{2}{|c|}{ Access this article online } \\
\hline Quick Response Code: & Website: \\
\hline & www.parjournal.net \\
\cline { 2 - 2 } & \\
\hline
\end{tabular}

demonstrated successful breast reconstruction with a transverse rectus abdominis myocutaneous flap after liposuction; however, there is a paucity of data on breast reconstruction using a deep inferior epigastric perforator (DIEP) flap after liposuction. ${ }^{[3-6]}$ Our experience

This is an open access article distributed under the terms of the Creative Commons Attribution-NonCommercial-ShareAlike 3.0 License, which allows others to remix, tweak, and build upon the work non-commercially, as long as the author is credited and the new creations are licensed under the identical terms.

For reprints contact: reprints@medknow.com

How to cite this article: Mankowski PJ, Kanevsky J, Lessard AS, Zadeh T. Free deep inferior epigastric perforator flap after abdominal liposuction: reconsidering a contraindication. Plast Aesthet Res 2015;2:311-4.

Received: 19-07-2015; Accepted: 29-09-2015 
of breast reconstruction with DIEP flap after abdominal wall liposuction will be demonstrated in addition to a literature review.

\section{METHODS}

An MEDLINE search was performed for all relevant articles describing the breast reconstruction with DIEP flap technique following abdominal wall liposuction. This study includes all published data on the topic from 1965 to December 2014. The PubMed database of the National Center for Biotechnology Information, National Library of Medicine (Bethesda, Maryland, USA), was used to collect reports using the keywords "DIEP”, "DIEAP”, "deep inferior epigastric perforator", "liposuction" and "free flap". All articles were reviewed for reports of clinical cases including complications, age, liposuction amount, time since liposuction and the number of perforators for comparison.

\section{RESULTS}

A total of 8 cases of autologous breast reconstruction using a DIEP flap after liposuction were identified in the literature review in addition to the 2 cases we present here. A study by De Frene et al. ${ }^{.71}$ describes five consecutive cases, and Jandali et al. ${ }^{[1]}$ reports one case. In addition, Farid et al. ${ }^{[8]}$ reported 2 cases involving DIEP flap breast reconstruction after multiple liposuction procedures. The results of these studies including our cases are summarized in Table 1 . The preoperative and postoperative course for all prior liposuction cases was uneventful except for our 2 patients: one who had a mild cellulitis that resolved with appropriate therapy without any compromise of the flap and another who experienced a hematoma which was subsequently drained. The average patient age was 52.2 years \pm 6.4 years old, and one perforator was used in all cases except one report where two were used. Of the reported cases, the average amount of liposuction collected was $1,084 \mathrm{~mL}$. Two minor complications out of the total 10 cases were a mild cellulitis and a postoperative stable hematoma. No major complications were reported.

Case I

A 50-year-old, nonsmoker, female underwent a left sided mastectomy for invasive ductal carcinoma. Conventional abdominal liposuction was performed 5 years before the original diagnosis of breast cancer. Three years after the mastectomy, the patient underwent autologous breast reconstruction with a DIEP flap. The patient was evaluated preoperatively for suitable perforators by computed tomography (CT) angiography and duplex ultrasound. Examination revealed appropriate perforator vessels and extensive fibrosis throughout the subcutaneous tissue caused by the previous liposuction. The patient underwent delayed unilateral breast reconstruction with a free DIEP flap. The postoperative course was complicated by a mild cellulitis that was successfully treated with antibiotics and no damage resulted to the flap [Figure 1].

\section{Case 2}

A 59-year-old, smoker, female with breast cancer underwent a right mastectomy in 1998 followed by implant-based reconstruction the same year. She later underwent radiation therapy and subsequently developed severe capsular contracture [Figure 2]. In 2012, she underwent right breast capsulectomy and reconstruction with DIEP flap. Eighteen years earlier, the patient had undergone conventional abdominal liposuction. The patient was evaluated preoperatively for suitable perforators by CT angiography and duplex ultrasound. Examination revealed appropriate perforator vessels. Three days following the DIEP flap procedure the patient developed a hematoma that was evacuated and the patient had a stable postoperative course without any flap compromise.

\section{DISCUSSION}

Previous literature suggests that harvesting perforator flaps from liposuctioned donor sites may not necessarily be a contraindication to free-flap breast reconstruction..$^{[5,7]}$ The largest reported series of DIEP flaps after liposuction was published by De Frene et al. ${ }^{[7]}$ with five successful cases of breast reconstruction. The DIEP flap, introduced by Itoh and Arai ${ }^{[9]}$ and Koshima and Soeda ${ }^{[10]}$ and popularized by Allen and Treece, ${ }^{[11]}$ Blondeel and Boeckx, ${ }^{[12]}$ and Blondee ${ }^{[13]}$ has been described as the most appropriate way to reconstruct a breast to minimize donor morbidity. ${ }^{[6,14,15]}$ The effect of liposuction on a free flap donor site months or years before flap transfer remains to be clarified.

Table 1: Summary of studies performing DIEP reconstruction in patients who have had previous liposuction

\begin{tabular}{|c|c|c|c|c|c|}
\hline Study & Age & Number of perforators & Liposuction (mL) & Years after liposuction & Complications \\
\hline Jandali et al..$^{[1]}$ & 42 & 2 & Not reported & 9 & None \\
\hline \multirow[t]{2}{*}{ Farid et al. ${ }^{[8]}$} & 57 & 1 & $240+300+300$ & 1.33 & None \\
\hline & 54 & 1 & 100 to $160 \times 5$ & 0.5 & None \\
\hline \multirow[t]{5}{*}{ De Frene et al. ${ }^{[7]}$} & 52 & 1 & 1,300 & 4 & None \\
\hline & 58 & 1 & 1,000 & 11 & None \\
\hline & 41 & 1 & 1,100 & 9 & None \\
\hline & 52 & 1 & 1,500 & 6.5 & None \\
\hline & 57 & 1 & 1,200 & 4 & None \\
\hline \multirow[t]{2}{*}{ Our study } & 50 & 1 & Not reported & 5 & Mild cellulitis \\
\hline & 59 & 2 & Not reported & 18 & Hematoma \\
\hline
\end{tabular}

DIEP: Deep inferior epigastric perforator 


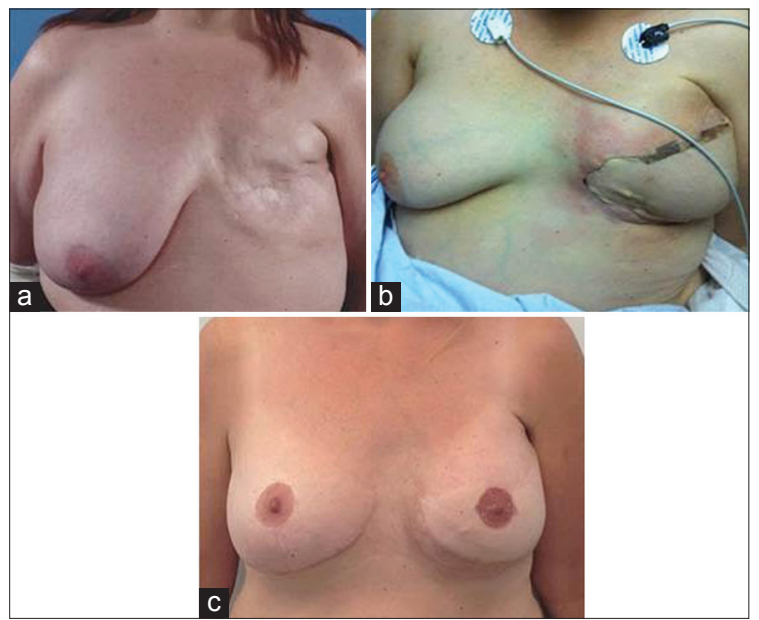

Figure 1: Case 1, patient before (a) and after (b), deep inferior epigastric perforator procedure with evidence of mild cellulitis surrounding the flap; (c) patient at 2 years follow-up after additional nipple reconstructive produces and extensive weight loss

Previous literature has shown conflicting evidence regarding the effect of liposuction on donor tissue, specifically, perforator vessels. Teimourian and Kroll ${ }^{[16]}$ reported that neurovascular bundles remain intact following conventional liposuction on examination with subcutaneous endoscopy. However, a study by Ozcan et al. ${ }^{[17]}$ demonstrated that flap necrosis is directly related to the number of suction passes of a cannula accompanied by a vacuum. İnceoğlu et al. ${ }^{[18]}$ reported a $57.8 \%$ decrease in the number of perforators in abdominal subcutaneous tissue 3 months after liposuction using duplex ultrasound. Despite the reported decrease in the number of perforators, Ribuffo et al..$^{[5]}$ demonstrated that perforator arteries regenerate up to $40 \%$ of their original diameter after liposuction. This evidence suggests that the liposuction technique may influence the degree to which perforator vessels are damaged and the outcome of the flap.

It should be possible to minimize patient complications associated with free-flap breast reconstruction after liposuction through modification of the initial liposuction procedure and decreasing trauma to perforators during liposuction. The variability in a number of perforators after liposuction is likely related to factors such as the cannula used, the number of passes, strength of suction and operator force and technique. An ultrasound-assisted liposuction technique described by Zocchi ${ }^{[19]}$ showed less damage to neurovascular structures. However, these findings were later opposed by a study which compared conventional versus ultrasonic liposuction. ${ }^{[2]}$ Salgarello et al. ${ }^{[20]}$ suggest employing a superficial subdermal liposuction technique to maintain perforator viability. Overall, a refined technique or protocol for liposuction in future free flap donor areas may improve patient outcome.

There are inherent difficulties in choosing when to use a technique to maximize perforator viability. For example, it is not possible to predict which patients will require autologous breast reconstruction with a free flap at the time of abdominal liposuction. Furthermore, patients may have breast reconstruction with a different surgeon than the one who performed the liposuction, creating

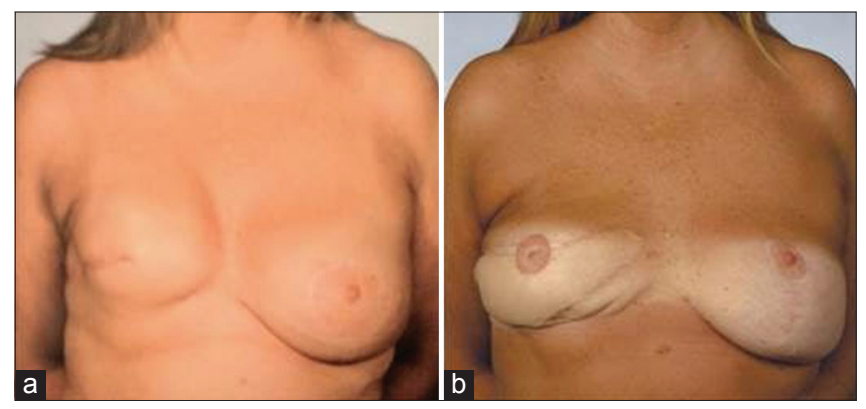

Figure 2: Case 2, (a) Patient prior to breast reconstruction with severe capsular contracture; (b) after DIEP flap procedure. DIEP: Deep inferior epigastric perforator

a challenge for the surgeon to predict the adequacy of perforators in the future donor site. As noted by Wes et al., ${ }^{[21]}$ breast reconstructive in the context of previous abdominal surgery therefore requires a thorough preoperative evaluation to prevent flap morbidity. Specifically in the context of liposuction, duplex ultrasound and CT angiography will help identify perforator viability to reduce procedural complications. The use of color duplex examination as a preoperative guide is reported to have a true-positive rate of $96.2 \%$ and a positive predictive value of $100 \%$ in the hands of an experienced sonographer. ${ }^{[22]}$ The use of CT angiography as a preoperative methodology was reinforced by both Bank et al. ${ }^{[23]}$ and Rozen et al..$^{[24]}$ to confirm perforator presence and communication for facilitating DIEP flap paddle design in postabdominal procedure patients. Rozen et al. ${ }^{[2]}$ highlighted the benefit of preoperative CT flap design as a method for identifying perforators resulted from neovascularization offering additional possibilities for DIEP harvesting. Other techniques such as flap perfusion mapping may be useful when the surgeon needs to know the integrity of vessels that are too small to image with standard angiographic techniques preoperatively. ${ }^{[25]}$ In addition, Masia et al. ${ }^{[26]}$ described multidetector-row CT, an imaging modality that allows for interpretation of a virtual anatomic dissection in three dimensions with very high spatial resolution. Intraoperative laser angiography using the SPY system has been shown to be beneficial for assessing tissue perfusion during flap elevation. ${ }^{[27]}$ Application of SPY laser angiography decreases the incidence skip necrosis in postmastectomy reconstruction and the rate of reoperation

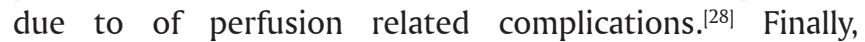
Farid et al. ${ }^{[8]}$ prefer MR angiography to CT angiography to avoid reliance on intravenous contrast and to reduce patient exposure to radiation. Appropriate application of these techniques for perforator evaluation including $\mathrm{CT}$, ultrasound, or perfusion mapping may improve the outcome of patients undergoing DIEP after abdominal liposuction

\section{CONCLUSION}

We have demonstrated two cases, in addition to the previously reported literature that suggest previous conventional liposuction is not an absolute contraindication for free-flap breast reconstruction. Preoperative management of the patient should include thorough evaluation of suitable 
perforators by duplex ultrasound or CT angiography. In patients with history of liposuction to the lower abdomen, a classification system would be of clinical utility in guiding the selection of the ideal technique for breast reconstruction. Larger case series are needed to better understand the safety of perforator flaps after liposuction.

\section{Financial support and sponsorship \\ Nil.}

\section{Conflicts of interest}

There are no conflicts of interest.

\section{REFERENCES}

I. Jandali S, Nelson JA, Wu LC, Serletti JM. Free transverse rectus abdominis myocutaneous flap for breast reconstruction in patients with prior abdominal contouring procedures. J Reconstr Microsurg 2010;26:607-I4.

2. Blondeel PN, Derks D, Roche N, Van Landuyt KH, Monstrey SJ. The effect of ultrasound-assisted liposuction and conventional liposuction on the perforator vessels in the lower abdominal wall. Br J Plast Surg 2003;56:266-7I.

3. Hess CL, Gartside RL, Ganz JC. TRAM flap breast reconstruction after abdominal liposuction. Ann Plast Surg 2004;53:166-9.

4. Karanas YL, Santoro TD, Da Lio AL, Shaw WW. Free TRAM flap breast reconstruction after abdominal liposuction. Plast Reconstr Surg 2003; | | 2:1851-4

5. Ribuffo D, Marcellino M, Barnett GR, Houseman ND, Scuderi N. Breast reconstruction with abdominal flaps after abdominoplasties. Plast Reconstr Surg 2001;108:1604-8.

6. Tachi M, Yamada A. Choice of flaps for breast reconstruction. Int J Clin Oncol 2005; 10:289-97.

7. De Frene B, Van Landuyt K, Hamdi M, Blondeel P, Roche N, Voet D, Monstrey S. Free DIEAP and SGAP flap breast reconstruction after abdominal/gluteal liposuction. J Plast Reconstr Aesthet Surg 2006;59:103 I-6.

8. Farid M, Nicholson S, Kotwal A, Akali A. DIEP breast reconstruction following multiple abdominal liposuction procedures. Eplasty 20।4; I4:e47.

9. Itoh $\mathrm{Y}$, Arai $\mathrm{K}$. The deep inferior epigastric artery free skin flap: anatomic study and clinical application. Plast Reconstr Surg 1993;91:853-63.

10. Koshima I, Soeda S. Inferior epigastric artery skin flaps without rectus abdominis muscle. BrJ Plast Surg 1989;42:645-8.

II. Allen RJ, Treece P. Deep inferior epigastric perforator flap for breast reconstruction. Ann Plast Surg 1994;32:32-8.
12. Blondeel PN, Boeckx WD. Refinements in free flap breast reconstruction: the free bilateral deep inferior epigastric perforator flap anastomosed to the internal mammary artery. Br J Plast Surg 1994;47:495-50I.

13. Blondeel PN. One hundred free DIEP flap breast reconstructions: a personal experience. BrJ Plast Surg 1999;52:104-II.

14. Arnez ZM, Pogorelec D, Planinsek F, Ahcan U. Breast reconstruction by the free transverse gracilis (TUG) flap. Br J Plast Surg 2004;57:20-6.

15. Hamdi M, Weiler-Mithoff EM, Webster MH. Deep inferior epigastric perforator flap in breast reconstruction: experience with the first 50 flaps. Plast Reconstr Surg 1999; 103:86-95

16. Teimourian B, Kroll SS. Subcutaneous endoscopy in suction lipectomy. Plast Reconstr Surg 1984;74:708-II.

17. Ozcan G, Shenaq S, Baldwin B, Spira M. The trauma of suction-assisted lipectomy cannula on flap circulation in rats. Plast Reconstr Surg 1991;88:250-8.

18. İnceoğlu S, Özdemir H, İnceoğlu F, Demir H, Önal B, Çelebi C. Investigation of the effect of liposuction on the perforator vessels using color Doppler ultrasonography. Eur J Plast Surg 1998;21:38-42.

19. Zocchi M. Ultrasonic liposculpturing. Aesthetic Plast Surg 1992;16:287-98.

20. Salgarello M, Barone-Adesi L, Cina A, Farallo E. The effect of liposuction on inferior epigastric perforator vessels: a prospective study with color Doppler sonography. Ann Plast Surg 2005;55:346-5I.

21. Wes AM, Cleveland E, Nelson JA, Fischer JP, Kovach SJ, Kanchwala S, Serletti JM, Wu LC. Do prior abdominal surgeries increase complications in abdominally based breast reconstructions? Ann Plast Surg 20I5;75:526-33.

22. Blondeel PN, Beyens G, Verhaeghe R, Van Landuyt K, Tonnard P, Monstrey S], Matton G. Doppler flowmetry in the planning of perforator flaps. BrJ Plast Surg 1998;51:202-9.

23. Bank J, Pavone LA, Seitz IA, Roughton MC, Schechter LS. CASE REPORT case report and review of the literature: deep inferior epigastric perforator flap for breast reconstruction after abdominal recontouring. Eplasty 2012; 12:e52

24. Rozen WM, Whitaker IS, Ting JW, Ang GG, Acosta R. Deep inferior epigastric artery perforator flap harvest after abdominoplasty with the use of computed tomographic angiography. Plast Reconstr Surg 2012;129:198e-200e.

25. May JW Jr, Silverman RP, Kaufman JA. Flap perfusion mapping: TRAM flap after abdominal suction-assisted lipectomy. Plast Reconstr Surg 1999; 104:2278-8I .

26. Masia J, Clavero JA, Larranaga JR, Alomar X, Pons G, Serret P. Multidetector-row computed tomography in the planning of abdominal perforator flaps. J Plast Reconstr Aesthet Surg 2006;59:594-9.

27. Gurtner GC, Jones GE, Neligan PC, Newman MI, Phillips BT, Sacks JM, Zenn MR. Intraoperative laser angiography using the SPY system: review of the literature and recommendations for use. Ann Surg Innov Res 2013;7:I.

28. Duggal CS, Madni T, Losken A. An outcome analysis of intraoperative angiography for postmastectomy breast reconstruction. Aesthet Surg J 20|4;34:6I-5. 